\title{
Estudo da demanda energética e desagregação do solo em diferentes sequências operacionais de preparo periódico ${ }^{1}$
}

\author{
Energetic demand and disaggregation of the soil in different operational sequencies \\ of periodic tillage
}

\author{
Nilson Salvador ${ }^{2}$, Renildo Luiz Mion ${ }^{3 *}$, Sérgio Hugo Benez e Carlos Alberto Viliotti $^{3}$
}

\begin{abstract}
Resumo - A correta seleção da sequência operacional do preparo do solo é fundamental para diminuir os custos da mecanização agrícola nas regiões que mobilizam intensamente o solo. Este trabalho teve como objetivo avaliar a demanda energética e a desagregação do solo em diferentes sequências operacionais de subsolagem e sistemas de preparo periódico do solo. $\mathrm{O}$ delineamento experimental utilizado foi em esquema fatorial $5 \mathrm{x} 2 \mathrm{com} 5$ repetições, com blocos dispostos ao acaso, sendo 5 sistemas de preparo do solo (D - Arado de discos, Dn - arado de discos seguido de uma grade niveladora, G Grade pesada, Gn - grade pesada seguida de uma grade niveladora e E - escarificador) e duas sequências de subsolagem (SP - Subsolagem - preparo e PS - Preparo - Subsolagem). Foram avaliados a demanda energética, o consumo de combustível por área e a desagregação do solo. Os resultados evidenciaram que a sequência operacional preparo do solo - subsolagem (PS) teve menor requerimento energético, com exceção do escarificador. A seqüência preparo do solo - subsolagem consumiu menos combustível e a desagregação do solo não apresentou variação estatística.
\end{abstract}

Palavras-chave - Agregação do solo. Preparo do solo. Mecanização agrícola.

\begin{abstract}
The correct selection of the operational sequence of soil tillage is essential to reduce the cost of agricultural mechanization in the regions that mobilize intensively the soil. The objective of this work was to evaluate the energetic demand and disaggregation of the soil in different operational sequences of subsoiling and systems of periodic soil tillage. The experimental design was blocks at random, in a factorial model $5 \times 2$ with 5 replications, being 5 tillage systems (D - Disc plow, Dn - disc plow followed at leveler rail, G - weight rail, Gn - weight rail followed of leveler rail and E - Stirrer. ) and two sequencies of subsoiling (SP - Subsoiling - tillage and PS - Tillage - subsoiling). There were evaluated the energetic demand, fuel consumption by area and the soil disaggregation. The results showed that the operational sequence tillage of the soil subsoiling (PS) had a lower energetic requirement, except for the stirrer, the sequence tillage the soil - subsoiling consumed less fuel and soil disaggregation didn't show statistic variation.
\end{abstract}

Keywords - Soil aggregation. Soil tillage. Agricultural mechanization.

\footnotetext{
* Autor para correspondência

${ }^{1}$ Recebido para publicação em 21/08/2009; aprovado em 30/04/2010

Pesquisa realizada no Departamento de Engenharia da Universidade Federal de Lavras com recursos da própria universidade

${ }^{2}$ Departamento de Engenharia, UFLA, Lavras-MG, Brasil, 37.200-000, Fone: (0xx) 35-3829-1466, salvador@ufa.br

${ }^{3}$ Departamento de Engenharia Agrícola, DENA/UFC, Fortaleza-CE, Brasil, rmion@ufc.br, viliotti@ufc.br

${ }^{4}$ Departamento de Engenharia Rural, FCA/UNESP, Botucatu-SP, Brasil, benez@fca.unesp.br
} 


\section{Introdução}

Para selecionar os sistemas de preparo periódico corretamente, devemos levar em consideração a demanda energética e características do solo como a textura e umidade. Maiores conhecimentos e domínios destas tecnologias podem levar a redução dos custos de produção das culturas (KICHLER et al., 2007). Segundo Mclaughlin et al. (2008), com uma seleção adequada do sistema de preparo do solo e correta adequação do trator e implemento, obtém-se redução na demanda energética de máquinas agrícolas. Avaliando o consumo energético de diferentes operações agrícolas mecanizadas, Fernandes et al. (2008) concluíram que os sistemas de preparo do solo, com menos operações por área, obtiveram menor consumo de combustível.

Salvador et al. (2008a), avaliando a demanda energética em diferentes sistemas de preparo periódico do solo realizado antes e depois da subsolagem, concluíram que o preparo do solo com escarificação obteve menor requerimento energético, quando realizado depois da subsolagem, entretanto, para os sistemas de preparo periódico do solo que utilizaram arado de discos e grades, apresentou melhor eficiência energética quando realizado antes da subsolagem.

Avaliando o requerimento energético em diferentes sistemas de preparo baseados em aração (discos e aivecas), gradagem (pesada e niveladora) e escarificação num Latossolo Vermelho Amarelo, Salvador et al. (1998) concluíram que a escarificação obteve menor demanda energética quando comparada aos demais sistemas de preparo estudados.

Avaliando diferentes sistemas de preparo do solo, Michel Junior et al. (1985) conseguiram uma redução de até $40 \%$ no requerimento energético na escarificação quando comparado ao arado de aivecas. $\mathrm{O}$ mesmo autor salienta que a correta seleção de sequência da operação é importante para aumentar o lucro dos agricultores.

Analisando o requerimento energético de diferentes sistemas de preparo reduzido e convencional do solo para a cultura do algodão irrigado, Coates e Thacker (1997) afirmaram que o sistema de preparo do solo reduzido diminuiu a mobilização da camada superficial do solo e exigiu menos energia quando comparado aos sistemas convencionais que mobilizam mais o solo. Ainda de acordo com os autores, os produtores podem conseguir redução no consumo de combustível sem alterar a produtividade, selecionando corretamente os sistemas de preparo do solo.

A avaliação energética pode ser realizada com base na medição do consumo de combustível por hectare, principal indicador técnico de referência na avaliação da eficiência de utilização do trator agrícola, uma vez que demonstra o envolvimento das diversas variáveis que condicionam o rendimento global da transformação do combustível fornecido ao motor em trabalho útil realizado pelo implemento, (SERRANO, 2007).

Abbaspour-Gilandeh et al. (2005) relatam uma economia no requerimento energético e no consumo de combustível da ordem de $50 \%$ e $30 \%$, respectivamente, conseguindo através da variação na profundidade de trabalho do arado de aivecas. A realização da subsolagem, depois dos sistemas de preparo periódico, requereu $15 \%$ menos potência na barra de tração do trator e economia de $16,5 \%$ de combustível por área (SALVADOR et al., 2008b).

Estudando a desagregação do solo provocada por um equipamento de preparo vertical do solo em diferentes velocidades e profundidades de trabalho, num Podzólico Vermelho, Amarelo Fernandes et al. (2001) concluíram que o diâmetro médio geométrico e o módulo de finura dos agregados do solo não variaram estatisticamente para a interação estudada. Carvalho Filho et al. (2007) concluíram que o preparo do solo com o escarificador atende à condição de manejo conservacionista por proporcionar agregados de maior tamanho e por manter elevada quantidade de resíduos na superfície do solo. Este trabalho teve o objetivo de estudar o requerimento energético e a desagregação do solo de diferentes sequências operacionais de preparo do solo.

\section{Material e métodos}

O experimento foi conduzido na Fazenda Experimental Lageado, Faculdade de Ciências Agronômicas, UNESP, Campus de Botucatu, Estado de São Paulo. A área experimental foi definida pelas seguintes coordenadas geográficas: a) Latitude Sul 2249'31" e Longitude Oeste 48 $25^{\prime} 37^{\prime \prime}$. A altitude e a declividade média são de $770 \mathrm{~m}$ e 2,5\%, respectivamente. A área estava sendo cultivada há vários anos com a cultura do milho, utilizando-se ininterruptamente o sistema convencional de preparo do solo (aração e gradagem).

Ascondições operacionaisdos equipamentosforam: a) arado de discos, de arrasto, com 4 discos de diâmetro de $710 \mathrm{~mm}$ e concavidade de $108 \mathrm{~mm}$, peso aproximado de $1.350 \mathrm{kgf}$ - sendo operado com ângulo vertical e horizontal dos discos de $22^{\circ}$ e $56^{\circ}$, respectivamente; b) grade aradora de discos, de arrasto, com controle de profundidade por rodas e levantamento através de sistema hidráulico, equipada com 10 discos recortados de $810 \mathrm{~mm}$ e concavidade de $101,6 \mathrm{~mm}$, espaçados de $440 \mathrm{~mm}$ e peso 
de $3.508 \mathrm{kgf}$ - sendo movimentada centralizada em relação ao trator e com ângulo de $45^{\circ}$ entre as seções; c) grade niveladora de discos, de arrasto, equipada com 32 discos de $508 \mathrm{~mm}$ e concavidade de $60 \mathrm{~mm}$, espaçados entre si de $167 \mathrm{~mm}$, peso de $687 \mathrm{kgf}$ - operaram centralizada em relação ao trator e com ângulo de $45^{\circ}$ entre as seções; d) escarificador de hastes rígidas, sem rolo destorroador, equipado com 10 hastes, distribuídas em 3 porta-hastes e ponteiras de $50 \mathrm{~mm}$ de largura e ângulo de ataque de $20^{\circ}$; e) subsolador de arrasto, com controle de profundidade por rodas e sistema de levantamento hidráulico, peso aproximado de $710 \mathrm{kgf}$, dotado de hastes parabólicas e com ponteiras aladas, equipado com três hastes, na configuração triangular, espaçadas entre si de $70 \mathrm{~cm}$; f) trator marca Valmet, modelo 128, 4x2 com tração dianteira auxiliar, com potência na TDP com rotação nominal do motor de $76,5 \mathrm{~kW}$, lastrado, com peso em ordem de marcha de $6900 \mathrm{kgf}$ e pneus dianteiros usados R-1 (14.9-26) - pressão de inflado de $95 \mathrm{kPa}$ e traseiros usados R-1 (18.4-34) - pressão de inflado de $110 \mathrm{kPa}$.

Para determinação da força de tração, foi utilizada uma célula de carga modelo $U 1$, precisão $\pm 0,3 \%$, capacidade de 5 ton, fabricado pela HBM, instalada entre a barra de tração e o cabeçalho de cada implemento.

A força média na barra de tração foi obtida utilizando a força integrada e o tempo gasto para percorrer $30 \mathrm{~m}$, que também foi utilizado para obtenção da velocidade de deslocamento, permitindo ainda o cálculo da potência na barra de tração, conforme Salvador et al. (2009b). A determinação da quantidade de energia requerida por área foi obtido por meio da equação 1:

$$
\begin{gathered}
E n=(P b \times T g s) \\
\text { em que: }
\end{gathered}
$$

$\mathrm{En}=$ Energia requerida por hectare $\left(\mathrm{kWh} \mathrm{ha}^{-1}\right)$,

$\mathrm{Pb}=$ Potência na barra de tração $(\mathrm{kW})$,

Tgs $=$ Tempo gasto para trabalhar 1 hectare $\left(\mathrm{h} \mathrm{ha}^{-1}\right)$,

$\mathrm{Na}$ determinação do consumo de combustível, utilizou-se um aparelho de medição direta, denominado Pierburg, modelo PLU 106, com capacidade de registro de até $60 \mathrm{~L} \mathrm{~h}^{-1}$, fornecendo o volume consumido por segundo. Após a obtenção dos valores do consumo horário de combustível, detrminou-se o consumo por área através da equação 2:

$$
C c=T g \times C h
$$

Em que:

$\mathrm{Cc}=$ Consumo de combustível por área $\left(\mathrm{L} \mathrm{ha}^{-1}\right)$,
$\mathrm{Tg}=$ Tempo gasto por ha,

$\mathrm{Ch}=$ Consumo horário de combustível $\left(\mathrm{L} \mathrm{h}^{-1}\right)$

O delineamento experimental utilizado foi um esquema fatorial com blocos dispostos ao acaso, com cinco repetições. Os cinco tratamentos de preparo do solo foram os seguintes: D - arado de discos, Dn - arado de discos seguido de uma gradagem leve, G - grade aradora, Gn - grade aradora seguida de uma gradagem leve e E - escarificador e duas sequências operacioanis: SP subsolagem - preparo e PS - preparo - subsolagem.

$\mathrm{Na}$ coleta do solo para determinação do diâmetro médio geométrico utilizou-se um equipamento construído em chapas de aço com as dimensões de $30 \times 30 \times 20 \mathrm{~cm}$, o qual foi cravado no meio de cada parcela experimental. Em seguida, foi acondicionado em caixas de papelão mantidas a $80{ }^{\circ} \mathrm{C}$ em estufa, com circulação forçada de ar, durante 24 horas. Após a estabilização da umidade das amostras os torrões foram passados em uma peneira concêntrica de vários diâmetros.

Para calcular o diametro médio geométrico foi utilizado a equação 3 :

$D M G=\operatorname{anti} \log \left[\frac{\sum_{i=1}^{n} W i \log d i}{\sum_{i=1}^{n} W i}\right]$

em que:

$\mathrm{Wi}=$ massa dos agregados retidos em cada classe de tamanho (g);

di = diâmetro de cada classe de torrões $(\mathrm{mm})$.

O módulo de finura foi calculado a partir da equação 4:

$M F=\frac{\sum \text { porcentagemacumulada }}{100}$

O solo utilizado para as determinações foi classificado como Nitossolo Vermelho Distroférrico, conforme (EMBRAPA, 1999), e textura argilosa (areia; 17,4\%; silte; $31,4 \%$ e argila $51,2 \%$ ). As operações de preparo periódico foram realizadas quinze dias antes da subsolagem, quando o solo apresentava, em média, teor de água de 0,19 e $0,26 \mathrm{~m}^{3} \mathrm{~m}^{-3}$, nas camadas de 0 a 10 e de 11 a $20 \mathrm{~cm}$ de profundidade, e densidade do solo de 1,40 e $1,41 \mathrm{Mg} \mathrm{m}^{-3}$, nas diferentes camadas, respectivamente. $\mathrm{O}$ preparo do solo foi realizado 17 dias depois da subsolagem, apresentando um teor de água de 0,18 e $0,25 \mathrm{~m}^{3} \mathrm{~m}^{-3}$ para as camadas de 0 a 10 e 11 a $20 \mathrm{~cm}$, respectivamente. 
Para medir a profundidade média de trabalho do arado, grade aradora e escarificador, utilizou-se um perfilômetro, descrito por Salvador et al. (1998), tomada de $50 \mathrm{em} 50 \mathrm{~mm}$ no sentido transversal da faixa trabalhada, encontrando os seguintes valores: 185; 160 e $169 \mathrm{~mm}$, respectivamente, enquanto que a profundidade do subsolador foi de $312 \mathrm{~mm}$.

\section{Resultados e discussão}

Na Tabela 1, observa-se que a análise de variância para a seqüência operacional estudada foi significativa a $5 \%$ de probabilidade para as variáveis energia e consumo de combustível, entretanto, para as variáveis diâmetro médio geométrico e módulo de finura, não ocorreu significância.

O sistema de preparo do solo, baseado em escarificação, apresentou a menor demanda energética da sequência operacional subsolagem-preparo (SP), quando comparado aos demais sistemas de preparo periódico. Esse comportamento se deve as semelhanças de ação dos órgãos ativos do escarificador e subsolador. O consumo de energia na combinação SP-E foi $24,5 \%$ menor que na combinação SP-G e 36,2 \% menor do que na combinação SP-Dn, conforme Tabela 2.

Na sequência operacional preparo seguido da operação de subsolagem (PS), a faixa resultante de consumo de energia teve uma menor amplitude do que na anterior, todavia a combinação E-PS ou escarificação mais subsolagem também apresentou o menor consumo de energia, com a economia de $16,7 \%$ em relação à pior combinação PS-Gn.

Comparando os resultados de cada sistema de preparo nas duas seqüências operacionais, verificase que, à exceção da combinação subsolagem escarificação que foi melhor na seqüência SP, a realização dos sistemas de preparo antes da subsolagem foi melhor, com economia de até $21,0 \%$ em energia para o tratamento com arado de discos e gradagem de nivelamento. A sequência subsolagem-preparo (SP) para a grade pesada seguida de uma grade niveladora teve uma demanda de energia de $13,6 \%$ superior ao preparo subsolagem (PS), devido a patinagem do trator e ação dos órgãos ativos do implemento.

Tabela 1 - Análise de variância dos parâmetros estudados nas seqüências operacionais

\begin{tabular}{lccccc}
\hline \multicolumn{1}{c}{ Fontes de variação } & Gl & Energia $\left(\mathrm{kWh} \mathrm{ha}^{-1}\right)$ & Cc $\left(\mathrm{L} \mathrm{ha}^{-1}\right)$ & DMG $(\mathrm{mm})$ & $\mathrm{MF}(\mathrm{mm})$ \\
\hline Blocos & 4 & $13,7366^{\mathrm{ns}}$ & $12,3294^{\mathrm{ns}}$ & $6,9854^{\mathrm{ns}}$ & $0,2422^{\mathrm{ns}}$ \\
Sist. de preparo & 4 & $1073,4554^{* *}$ & $304,2985^{* *}$ & $4,9289^{\mathrm{ns}}$ & $0,2131^{\mathrm{ns}}$ \\
Seq. operacional & 1 & $2093,2909^{* *}$ & $763,4747^{*}$ & $11,8974^{\mathrm{ns}}$ & $0,4600^{\mathrm{ns}}$ \\
Sist. de preparo x seq. operacional & 4 & $245,5087^{* *}$ & $56,0621^{* *}$ & $2,4760^{\mathrm{ns}}$ & $0,1032^{\mathrm{ns}}$ \\
Erro & 36 & 7,0382 & 5,7697 & 3,4691 & 0,1256 \\
Total & 49 & & & & \\
Cv $(\%)$ & & 3,02 & 5,31 & 25,02 & 8,77 \\
\hline
\end{tabular}

Ns - não significativo, ${ }^{* *}$ significativo a $5 \%$ de probabilidade

Tabela 2 - Demanda de energia por hectare $\left(\mathrm{kWh} \mathrm{ha}^{-1}\right)$ nas seqüências operacionais

\begin{tabular}{|c|c|c|c|}
\hline \multicolumn{4}{|c|}{ Energia $\left(\mathrm{kWh} \mathrm{ha}^{-1}\right)$} \\
\hline \multirow{2}{*}{ Sistemas de preparo } & \multicolumn{2}{|c|}{ Seqüências Operacionais } & \multirow{2}{*}{ Diferença $(\%)$} \\
\hline & $\mathrm{SP}$ & PS & \\
\hline Arado de discos & $97,67 \mathrm{Cb}$ & $81,55 \mathrm{BCa}$ & $-16,5$ \\
\hline Arado de discos seguido de uma grade niveladora & $109,36 \mathrm{Db}$ & $86,35 \mathrm{CDa}$ & $-21,0$ \\
\hline Grade pesada & $92,35 \mathrm{Bb}$ & $76,97 \mathrm{Aba}$ & $-16,7$ \\
\hline Grade pesada seguida de uma grade niveladora & $101,83 \mathrm{Cb}$ & $88,01 \mathrm{Da}$ & $-13,6$ \\
\hline Escarificador & $69,72 \mathrm{Aa}$ & $73,35 \mathrm{Ab}$ & 5,2 \\
\hline Média & $94,19 \mathrm{~b}$ & $81,25 \mathrm{a}$ & $-13,1$ \\
\hline
\end{tabular}

Médias seguidas de mesma letra maiúscula na coluna e de mesma letra minúscula na linha não diferem entre si, a 5\% de probabilidade, pelo teste de Tukey 
A média geral de energia requerida nas sequências operacionais mostra que a seqüência preparo-subsolagem (PS) é mais econômica energeticamente, pois foi 13,1\% menor do que a seqüência subsolagem-preparo (SP). Essas observações reforçam as afirmações de Michel Júnior et al. (1985) de que a energia requerida nas operações de preparo do solo depende da sequência de realização das mesmas, da patinagem do trator, bem como dos implementos utilizados.

Nas duas sequências operacionais, os maiores volumes de combustível foram verificados para os sistemas que envolveram mais de uma operação de preparo periódico (Tabela 3). Na seqüência SP, a combinação subsolagem-escarificação resultou em uma economia de 33,2 e $32,7 \%$ de óleo diesel por hectare, em relação às combinações subsolagem-gradagem pesada (SP-Gn) e subsolagem-aração (SP-Dn), respectivamente, o que reforça a viabilidade dos sistemas baseado em escarificação, verificada por Michel Júnior et al. (1985) e Salvador et al. (2009a).

Analisando o consumo de combustível por hectare nas seqüências operacionais, para cada sistema de preparo, observa-se que, de um modo geral, a realização do preparo antes da subsolagem foi melhor do que na sequência usada tradicionalmente (SP). Os volumes de combustíveis nas duas seqüências operacionais foram estatisticamente iguais quando realizada a escarificação.

A análise baseada na média geral de cada sequência mostra a superioridade da sequência (PS) (preparo-subsolagem), a qual proporcionou uma redução média de $15 \%$ no consumo de combustível por hectare. É importante salientar que a regulagem do ângulo dos discos do arado deve-se levar em consideração as condições de compactação do solo, umidade, cobertura vegetal, entre outras características inerentes.

Os resultados mostram que o diâmetro médio geométrico (DMG) não variou estatisticamente dentro de cada seqüência operacional (Tabela 4). Os resultados do módulo de finura (MF) variaram apenas na sequência operacional subsolagem seguida de preparo periódico do solo (SP), sendo o maior valor para o sistema de preparo com aração (D). Nota-se também certa proporcionalidade entre o gasto de energia e de combustível por hectare com o grau de mobilização do solo.

Tabela 3 - Volume de combustível necessário por hectare $\left(\mathrm{L} \mathrm{ha}^{-1}\right)$ para execução de cada seqüência operacional

\begin{tabular}{llcc}
\hline \multicolumn{3}{c}{ Consumo Combustível $\left(\mathrm{L} \mathrm{ha}^{-1}\right)$} & \\
\hline \multirow{2}{*}{ Sistemas de preparo } & \multicolumn{2}{c}{ Seqüências Operacionais } & \multirow{2}{*}{ Diferença (\%) } \\
\cline { 2 - 3 } & \multicolumn{1}{c}{$\mathrm{SP}$} & $37,65 \mathrm{Aa}$ & $-22,2$ \\
\hline Arado de discos & $48,38 \mathrm{Bb}$ & $44,44 \mathrm{Ba}$ & $-20,4$ \\
\hline Arado de discos seguido de uma grade niveladora & $55,80 \mathrm{Cb}$ & $41,56 \mathrm{Aba}$ & $-13,3$ \\
\hline Grade pesada & $47,93 \mathrm{Bb}$ & $45,68 \mathrm{Ba}$ & 18,7 \\
\hline Grade pesada seguida de uma grade niveladora & $56,19 \mathrm{Cb}$ & $-0,3$ \\
\hline Escarificador & $37,53 \mathrm{Aa}$ & $37,42 \mathrm{Aa}$ & $-15,0$ \\
\hline Média & $49,17 \mathrm{~b}$ & $41,35 \mathrm{a}$ & \\
\hline
\end{tabular}

Médias seguidas de mesma letra maiúscula na coluna e de mesma letra minúscula na linha não diferem entre si, a $5 \%$ de probabilidade, pelo teste de Tukey

Tabela 4 - Diâmetro médio geométrico (mm) e módulo de finura de agregados do solo após a realização das seqüências operacionais

\begin{tabular}{|c|c|c|c|c|}
\hline \multirow{3}{*}{ Sistemas de Preparo } & \multicolumn{4}{|c|}{ Seqüências Operacionais } \\
\hline & \multicolumn{2}{|c|}{$\mathrm{DMG}(\mathrm{mm})$} & \multicolumn{2}{|c|}{ MF } \\
\hline & $\mathrm{SP}$ & PS & SP & PS \\
\hline Arado de discos & $8,51 \mathrm{~A}$ & $8,37 \mathrm{~A}$ & $4,26 \mathrm{~B}$ & $4,22 \mathrm{~A}$ \\
\hline Arado de discos seguido de uma grade niveladora & $6,81 \mathrm{~A}$ & $7,76 \mathrm{~A}$ & $3,94 \mathrm{AB}$ & $4,10 \mathrm{~A}$ \\
\hline Grade pesada & $7,38 \mathrm{~A}$ & $7,67 \mathrm{~A}$ & $4,02 \mathrm{AB}$ & $4,10 \mathrm{~A}$ \\
\hline Grade pesada seguida de uma grade niveladora & $5,26 \mathrm{~A}$ & $7,68 \mathrm{~A}$ & $3,52 \mathrm{~A}$ & $4,08 \mathrm{~A}$ \\
\hline Escarificador & $6,82 \mathrm{~A}$ & $8,18 \mathrm{~A}$ & $3,94 \mathrm{AB}$ & $4,18 \mathrm{~A}$ \\
\hline
\end{tabular}

Médias seguidas de mesma letra maiúscula na coluna e de mesma letra minúscula na linha não diferem entre si, a 5\% de probabilidade, pelo teste de Tukey 


\section{Conclusões}

1. Os resultados evidenciaram que a sequência operacional preparo do solo - subsolagem teve menor requerimento energético, com exceção do escarificador.

2. A sequência preparo do solo 0 - subsolagem consumiu menor volume de combustível e a desagregação do solo não variou estatisticamente.

\section{Referências}

ABBASPOUR-GILANDEH, Y. et al. Energy savings with variable-depth tillage. Proceedings of the 2005 Southern Conservation Tillage Systems Conference, Florence, South Carolina, USA. 2005.

CARVALHO FILHO, A. et al. Métodos de preparo do solo: alterações na rugosidade do solo. Engenharia Agrícola, v. 27, n. 01, p. 229-237, 2007.

COATES, W.; THACKER, G. Reduced tillage systems for irrigated cotton: energy requirements and crop response. Applied Engineering in Agriculture, v. 13, n. 01, p. 31-34, 1997.

EMPRESA BRASILEIRA DE PESQUISA AGROPECUÁRIA (EMBRAPA). Centro Nacional de Pesquisas de Solos. Sistema Brasileiro de Classificação de Solos. Brasília, 1999. 412 p.

FERNANDES, H. C. et al. Avaliação operacional de um equipamento conjugado de preparo vertical com relação a desagregação do solo. Engenharia Agrícola, v. 21, n. 02, p. 190-196, 2001.

FERNANDES, H. C.; SILVEIRA, J. C. M. da; RINALDI, P. C. N. Avaliação do custo energético de diferentes operações agrícolas mecanizadas. Ciência e agrotecnologia, v. 32, n. 05, p. $1582-1587,2008$.
KICHLER, C. M. et al. Spatially Monitoring Tractor Performance to Evaluate Energy Requirements of Variable Depth Tillage and Implement Selection. American Society of Agricutural and Biological Engineers, n. 071028. 2007.

MCLAUGHLIN, N. B. et al. Energy inputs for conservation and conventional primary tillage implements in a clay loam soil. Transactions of the ASABE, v. 51, n. 04, p. 1153-1163. 2008.

MICHEL JUNIOR, J. A.; FORNSTROM, K. J.; BORELLI, J. Energy requirements of two tillage systems for irrigated sugarbeets, dry beans and corn. Transactions of the ASAE, v. 28, n. 06, p. 1731-1735, 1985.

SALVADOR, N.; MION, R. L.; BENEZ, S. H. Requerimento energético e desagregação do solo em diferentes sistemas de preparo periódico num Latossolo Vermelho Amarelo. Revista Engenharia na Agricultura, v. 06, n. 04, p. 226-234, 1998.

SALVADOR, N.; BENEZ, S. H.; MION, R. L. Demanda energética em diferentes sistemas de preparo periódico do solo antes e depois da subsolagem. Revista Ciência Agronômica, v. 39 , n. 03, p. 378-383, 2008a.

SALVADOR, N.; BENEZ, S. H.; MION, R. L. Consumo de combustível na operação de subsolagem realizada antes e depois de diferentes sistemas de preparo periódico do solo. Engenharia Agrícola, v. 28, n. 02, p. 256-262, 2008b.

SALVADOR, N.; MION, R. L.; BENEZ, S. H. Consumo de combustível em diferentes sistemas de preparo periódico realizados antes e depois da operação de subsolagem. Ciência e agrotecnologia, v. 33, n. 03, p. 870-874, 2009a.

SALVADOR, N.; BENEZ, S. H.; MION, R. L. Demanda energética na subsolagem realizada antes e depois de diferentes sistemas de preparo periódico do solo. Revista Ciência Rural, v. 39 , n. 09 , p. $2501-2505,2009$ b.

SERRANO, J. M. P. R.. Desempenho de tratores agrícolas em tração. Pesquisa Agropecuária Brasileira, v. 42, n. 07, p. 10211027, 2007. 